\title{
CORPO E OUTRAS (DE)LIMITAÇŌES SEXUAIS Uma análise antropológica da revista Sexuality and Disability entre os anos de 1996 e 2006*
}

\author{
Nádia Elisa Meinerz
}

Há mais de vinte anos as abordagens construtivistas vêm se afirmando a partir da contraposição às leituras médicas e sexológicas da sexualidade. Tais abordagens produziram um importante referencial sobre diversidade sexual e de gênero, amplamente utilizado para instrumentalizar a idéia dos direitos sexuais e reprodutivos como direitos humanos. $\mathrm{O}$ tema das "deficiências", ${ }^{1}$ nesse contexto, descortina uma "nova pauta" de pesquisa em relação às convençôes corporais relacionadas com sexualidade e gênero. Ele remete a uma discussão sobre limites para o exercício da sexualidade no que concerne à presença de "deficiências" cognitivas e físicas e de

* Esse artigo foi apresentado no $32^{\circ}$ Encontro Anual da Anpocs, no grupo de trabalho "Corpo, Gênero e Sexualidade”, coordenado por Júlio Assis Simões e Adriana Vianna em outubro de 2008 em Caxambu-MG.

Artigo recebido em novembro/2008

Aprovado em janeiro/2010 doença crônicas. Ao mesmo tempo, suscita um questionamento sobre a opressão das convençōes corporais relativas à sexualidade (relação heterossexual e penetrativa) para as pessoas com "deficiência”. Apesar de constituir uma novidade, muito poucos pesquisadores dessa área têm se apropriado dos referenciais que enfatizam a variabilidade das experiências sexuais e sua potencialidade na produção de subjetividades para pensar essa temática.

$\mathrm{Na}$ contramão dessa tendência, pode-se observar uma significativa mobilização para a produção de alternativas médico-químicas e psicológicas para viabilizar o exercício da sexualidade entre pessoas com "deficiências" físicas, bem como estratégias para conter os excessos sexuais das pessoas com "deficiências" cognitivas. Nesse sentido, o cruzamento entre sexualidade e "deficiência" mobiliza a produção de um conhecimento que dê sustentação à prática clínica em diferentes áreas, como a sexologia, a medicina de reabilitação, a enfermagem, a fisiote- 
rapia, a psicologia, além de mobilizar uma série de outros interesses jurídicos, políticos e tecnológicos.

O objetivo desse texto é explorar a emergência da interface entre sexualidade e "deficiência", tomando como foco a análise dos artigos de um periódico internacional, que desde o final da década de 1970 propóe associar as duas temáticas. Publicada pela primeira vez em $1978,{ }^{2}$ a revista Sexuality and Disability propõe abarcar os aspectos médicos, psicológicos e sociais da sexualidade relacionados com a reabilitação dos mais diversos tipos de "deficiências". Em sua origem, a sexualidade é considerada, essencialmente, parte de um processo mais amplo de reabilitação das pessoas com "deficiência". Os centros de pesquisa que sustentam as primeiras publicações são faculdades de medicina e reabilitação, entidades de proteção aos veteranos de guerra e centros públicos e privados de reabilitação. ${ }^{3}$

Foram selecionados para análise dez volumes publicados entre os anos de 1997 e 2009, período no qual a revista esteve sob a coordenação editorial do sexólogo e terapeuta sexual, Stanley Ducharme. Os textos consistem em pesquisas acadêmicas, estudos de casos, relatos de prática clínica, questôes levantadas pelos consumidores, ${ }^{4}$ programas comunitários, programas para vida independente; orientaçôes para prática clínica, desenvolvimentos em programas especiais de educação sexual e aconselhamento para pessoas com "deficiência". Com base em uma leitura etnográfica dos artigos são identificadas quatro perspectivas de articulação entre as temáticas que remetem a problemas de investigação distintos, a modelos específicos de explicação da "deficiência", a diferentes áreas profissionais ou científicas e ainda a posições variáveis em relação à produção, à aplicação e ao consumo do conhecimento científico. Essas perspectivas foram agrupadas em uma proposta tipológica que separa a ênfase no funcionamento sexual, a preocupação com as especificidades das mulheres com "deficiência", a perspectiva da desabilitação e as redes de suporte e assistência.

Discute-se ainda a discrepância numérica em favor dos artigos que abordam "deficiências" físicas em relação aos que tematizam "deficiências" cognitivas e doenças degenerativas relacionadas com o envelhecimento, sobretudo ao sentido que a sexua- lidade assume em cada tipo de "deficiência". Os dados apontam para a sexualidade como um dispositivo de fronteira no que diz respeito ao acesso à normalidade, operando ora como atestado de uma reabilitação satisfatória dos sujeitos, ora como evidência da anormalidade. Antes, porém, de adentrar essa discussão, explicito o percurso metodológico desse trabalho, com especial atenção para a descrição da organização formal e uma breve contextualização da heterogeneidade de seu conteúdo.

\section{Uma revista como "campo" de pesquisa}

O interesse pela "deficiência" origina-se nas discussões de um grupo de trabalho sobre direitos sexuais e reprodutivos como direitos humanos. ${ }^{5}$ Nesse âmbito, a proposta atraiu a atenção de uma entidade da sociedade civil vinculada a um grupo religioso (evangélico tradicional), a qual organizava ações de inclusão social de crianças e jovens com Síndrome de Down. Com uma postura bastante progressista, as profissionais da área de psicologia, pedagogia e assistência social da instituição manifestavam seu desconforto profissional em utilizar "medidas repressivas" como único recurso diante das manifestaçōes "sexuais" de crianças e jovens Down. Era necessário pois construir alternativas de manejo da sexualidade que tivessem maior respaldo científico e, ao mesmo tempo, amparo legal.

$\mathrm{Na}$ busca de um embasamento teórico que pudesse contribuir nesse sentido, a revista Sexuality and Disability, acessada no portal de periódicos da Capes, foi privilegiada como fonte bibliográfica. No entanto, com o contato mais próximo ao conteúdo dos artigos, a própria revista foi se convertendo em objeto de reflexão, pela multiplicidade de abordagens, muitas vezes contraditórias, em torno das quais são propostas articulaçôes entre as duas temáticas. Tais abordagens remetem a uma negociação complexa sobre os limites e as potencialidades sexuais colocados pela variação corporal, seja ela resultante de uma "deficiência" cognitiva ou física, de origem congênita ou adquirida, seja pela "degradação" relativa aos processos de adoecimento físico e psíquico. Ao mesmo tempo, elas estabele- 
cem prescrições e proibições no âmbito das interaçôes sociais e sexuais entre as pessoas consideradas normais e aquelas portadoras de algum tipo de "deficiência". A revista pode ser considerada, no sentido antropológico do termo, um "campo" profícuo para a investigação das perspectivas de articulação entre as duas temáticas.

Do ponto de vista metodológico, a leitura antropológica dos artigos publicados nesse periódico implica uma apropriação da etnografia como ferramenta útil para a descrição e a análise de outros objetos que não pessoas em seus valores e práticas cotidianas. Para tanto, as análises realizadas a seguir estão fundamentadas na discussão proposta por Adriana Vianna (2006) sobre a etnografia de documentos. Dirigida a esse campo específico, a abordagem etnográfica supõe que se persiga a trilha das condiçôes da produção de "verdades", "informaçōes", "práticas", "dados" e "recomendaçōes" enunciados nos artigos analisados.

Cada um dos artigos faz parte de um determinado contexto de produção de conhecimento, está inserido numa certa tradição disciplinar, possui objetivos específicos em relação à publicação e, principalmente, constrói a relação entre sexualidade e "deficiência" de uma maneira particular. Ao mesmo tempo, todos eles compartilham (como documentos de um arquivo) certa padronização formal e são avaliados a partir do estatuto, ou do lugar que a revista ocupa em relação às hierarquias de credibilidade do campo editorial. Importa questionar sobre o ato da publicação em si, sobre a seleção do que merece ser publicado, sobre o "julgamento editorial” do que contribuirá para a articulação entre as duas temáticas. Nesse âmbito, não só é necessário atentar para o que os artigos efetivamente mostram, mas também questionar sobre o que eles silenciam (Vianna, 2006).

Em suma, pode-se dizer que a proposta aqui consiste em fazer com os artigos da revista Sexuality and Disability um pouco daquilo que os antropólogos fazem com as situações de trabalho de campo. Isso implica não apenas descrever o maior número possível de situações, mas também atentar para detalhes aparentemente banais, selecionar determinados artigos e passagens que se tornaram marcantes ao longo da leitura porque ajudaram a construir uma coerência diante da multiplicidade de abordagens que perpassa a revista.

A inserção nesse "campo" de pesquisa possibilita um diálogo com os estudos de antropologia e sociologia que têm como objeto a análise da ciência. Embora não se trate de estudar um tipo específico de produção e prática científica (como a de laboratório) nem de um campo disciplinar (como a medicina), a análise da revista em pauta pode contribuir para uma abordagem das dinâmicas sociais que perpassam a produção de fatos científicos. Isso porque a revista coloca em evidência disputas e alianças entre atores, saberes e campos disciplinares que operam a partir de concepções de ciência e de critérios de cientificidade diferentes. Tais relações concorrem para a emergência de diferentes interfaces entre sexualidade e "deficiência".

Para compreender esse processo, privilegia-se o conceito de problematização, desenvolvido por Foucault (2004) na esteira das discussões sobre ciência propostas por Georges Canguilhein. Seguindo a orientação de outros trabalhos que propõem uma leitura metodológica desse conceito, considera-se a noção de problematização uma ferramenta de investigação mais do que uma teoria explicativa. ${ }^{6}$ Nesse sentido, o texto remete à maneira pela qual um objeto se torna problema para o pensamento mediante práticas discursivas e não discursivas que o inserem num determinado "regime de verdades" (Idem, p. 242). Trata-se de compreender as formas de articulação entre os discursos sobre sexualidade e os discursos sobre "deficiência" na conformação de problemas específicos.

\section{Descrevendo a revista e contextualizando o "campo"}

Os volumes publicados entre 1997 e 2006 comportam quatro números anuais, em que são apresentados entre cinco e oito artigos. Embora a estrutura não seja fixa, há um padrão de apresentação, composto por notas de edição, artigos, resenhas, anúncios, sumário e listagem de editores convidados para os próximos volumes. Alguns números organizam-se em tópicos especiais para os quais são chamados editores convidados. ${ }^{7}$ Outros são inteira- 
mente dedicados à transcrição de resumos e principais artigos apresentados em congressos internacionais. Essas publicações abrangem diferentes tipos de eventos, como aqueles realizados por militantes, ou grupos profissionais além daqueles de caráter acadêmico. ${ }^{8}$ Uma outra modalidade são as compilações bibliográficas, geralmente organizadas pelo editor convidado dos tópicos especiais.

$\mathrm{O}$ caráter menos acadêmico de alguns artigos pode ser evidenciado principalmente em volumes não organizados em torno de um tópico especial. Nestes, não é incomum encontrar textos em estilo de depoimento, de autores qualificados como "consumidores" dos serviços de reabilitação. O relato de casos ou de estratégias terapêuticas empregados por profissionais, principalmente da área da psicologia, também encontram ali um importante espaço de expressão.

Além da sessão de artigos, a revista comporta ainda uma sessão de resenhas (composta geralmente por uma ou no máximo duas resenhas) de livros ou filmes que vinculem de alguma maneira a temática da sexualidade à da deficiência, ou que abordem pelo menos uma das duas. Aqui novamente encontramos o espaço para a realização de comentários, reflexões e divulgação dos mais diversos tipos de literatura.

A edição fecha com a previsão de tópicos especiais e editores convidados, além de anúncios das mais diferentes ordens: divulgação de eventos, concursos acadêmicos e bolsas de pesquisa, propaganda de programas terapêuticos, cursos e ações de formação e treinamento para cuidadores e trabalhadores da área da saúde, e até convocações dirigidas à população desabilitada para participação em pesquisas científicas.

Esse tipo de organização contrasta bastante com outros periódicos da área médica, principalmente no que diz respeito ao grau de especialização das temáticas e à homogeneidade dos artigos acolhidos para a publicação. O que marca a revista Sexuality and Disability é justamente a heterogeneidade ${ }^{9}$ de seu conteúdo e a explicitação de uma complexa rede de articulações entre os atores envolvidos na produção, na aplicação e no consumo do conhecimento científico. Essa característica deve ser considerada em relação ao lugar ocupado pela sexo- logia e pela medicina de reabilitação no campo de lutas por posição, prestígio e recursos biomédicos. Nesse sentido, a medicina de reabilitação pode ser pensada a partir da diferenciação valorativa entre disciplinas diagnósticas e terapêuticas proposta por Camargo Jr. (2003). Relacionadas com a modalidade terapêutica, ambas as especialidades são menos valorizadas e menos reconhecidas do ponto de vista científico.

Mesmo em relação à prática médica, que segundo Camargo Jr. (2003) é lócus privilegiado para mudanças valorativas (no qual a cirurgia, por exemplo, se destaca em termos reconhecimento) a posição da reabilitação não é diferente. Isso porque essa especialidade é perpassada por uma incontornável tensão entre a expectativa de cura ou erradicação da doença (importante objetivo da medicina) e a sua impossibilidade ante a deficiência. A prática médica de reabilitação é desprestigiada porque evidencia os limites da atuação médica na superação da "deficiência”, constituindo-se numa espécie de medida paliativa. Assim, pode-se argumentar que o manejo médico das "deficiências" segue uma tendência de maior abertura para a multidisciplinaridade, que já foi observada por Menezes (2004) em relação à emergência dos cuidados paliativos.

Uma outra tendência, diante da impossibilidade de cura ligada à "deficiência", é o deslocamento do lugar do paciente dentro da cena médica. Como ressalta Ducharme, em um de seus editoriais de despedida, a própria criação da revista resulta desse deslocamento: do paciente como ouvinte passivo das recomendaçôes clínicas para consumidor dos serviços de saúde, dos recursos tecnológicos e do próprio conhecimento científico. Segundo sua descrição:

A idéia de proporcionar educação sobre sexualidade é uma coisa única para o campo da medicina de reabilitação. $\mathrm{Na}$ verdade, apenas desde meados da década de 1970 é que as pessoas começaram a falar sobre sexualidade como parte do processo de reabilitação. Antes disso, nem mesmo os médicos consideravam que você pudesse ter uma vida sexual após uma lesão grave. Eles acreditavam que a sua vida sexual terminava a partir do momento em que você se tornava uma pessoa com lesão na co- 
luna vertebral. Em conseqüência, o assunto foi evitado ou ignorado.

Não por acaso, foram as próprias pessoas vinculadas aos programas pela vida independente e consumidores com lesão da coluna vertebral que começaram a buscar esse tipo de informação de seus médicos. Os consumidores dos serviços de reabilitação mudaram o stablichment médico. Eles queriam ter uma vida sexual. Seus relacionamentos conjugais eram importantes pra eles. Os pacientes começaram a falar sobre sexo entre si e apelar aos médicos, quando tinham dúvidas. Naquela época, os médicos prestadores de serviço também estavam embaraçados em falar sobre sexo, mas eles não tinham outra escolha, a não ser responder a esses questionamentos (Ducharme, 2005, p. 117, trad. livre).

Resgatando os elementos que desencadearam a organização da revista, o autor assinala que a iniciativa de abordar a sexualidade nos processos de reabilitação é dos próprios pacientes. Essa demanda impulsionou a realização das primeiras pesquisas sobre implante peniano entre homens com lesão da coluna vertebral. Tal técnica foi, até a invenção do viagra, uma das mais difundidas nos processos de reabilitação sexual, muito embora sua utilização implicasse vários riscos para os pacientes.

\section{Convençôes corporais e (de)limitações sexuais}

A emergência da interface entre sexualidade e "deficiência" como objeto de produção de conhecimento conforma diferentes possibilidades de problematização relacionadas não só com as diferenças disciplinares, mas também com uma complexa rede de relaçôes políticas, interesses econômicos e de normatizações jurídicas. Nesta sessão, apresento uma proposta tipológica das formas de problematização encontradas nos artigos da revista Sexuality and Disability. É importante destacar que, a despeito do investimento tipológico realizado, não se trata aqui de enquadrar cada um dos artigos da revista numa dessas perspectivas. Pelo contrário, muitos artigos podem conformar a um só tempo mais de uma dessas perspectivas e outros, ainda, parecem inclassificáveis.

\section{A funcionalidade sexual}

A ênfase majoritária nos processos de reabilitação fornece uma pista importante sobre a preocupação mais típica dos objetos de investigação que perpassam os artigos da revista: a funcionalidade sexual. Nesse sentido, o discurso sexológico desponta como principal referencial tanto no campo da pesquisa como no da proposição terapêutica, embora não exclusivamente. As principais áreas do conhecimento empenhadas na construção desse tipo de problema são a medicina (com grande destaque para a urologia) e a psicologia, além da biologia molecular, cuja expressividade vem aumentando nos três últimos anos principalmente no campo da disfunção erétil e das patologias relativas à diferenciação sexual. Nessa perspectiva privilegiase a influência sobre o funcionamento sexual dos mais diferentes tipos de "deficiência", tanto no que diz respeito ao comprometimento corporal e aos limites que este estabelece para o desempenho da atividade sexual, como no que concerne aos aspectos psicológicos decorrentes ou não de condiçôes físicas. Outro foco privilegiado para esse tipo de estudo é o impacto sobre o funcionamento sexual da utilização de medicamentos e técnicas terapêuticas de combate a doenças crônicas. Exemplo disso aparece no quarto número do vigésimo volume, publicado em dezembro de 2002, inteiramente dedicado ao impacto de diversos tipos de câncer sobre a sexualidade, principalmente no que diz respeito ao uso de técnicas radio e quimioterápicas.

Ao mesmo tempo, as próprias patologias físicas e psíquicas desencadeadoras de comprometimento para a atividade sexual normal (como a disfunção erétil) são consideradas, nessa perspectiva, formas de deficiência. Aproveitando-se desse deslizamento semântico, a própria psiquiatria ganha espaço em meio ao discurso sobre a funcionalidade, ao destacar os distúrbios do comportamento sexual associados à transexualidade, às diferentes formas de fetichismo, ao devoteísmo ${ }^{10} \mathrm{e}$ até mesmo à homossexualidade. ${ }^{11}$ 
Os estudos que assumem a problemática da funcionalidade estão empenhados tanto na descoberta das causas orgânicas e psicológicas de prejuízo da atividade sexual (numa atuação mais diagnóstica), como na produção de medicamentos, técnicas cirúrgicas, desenvolvimento de próteses e outras estratégias terapêuticas de reabilitação. Também se observa uma preocupação com a redução dos efeitos colaterais de diversos tipos de medicamentos utilizados em pacientes psiquiátricos e com outras doenças crônicas. No campo da psicologia, destacam-se o desenvolvimento e a avaliação de escalas de mensuração da satisfação e da auto-estima sexuais.

É importante ressaltar que a preocupação com o funcionamento sexual no campo da sexologia não se restringe à questão das "deficiências". Ela deve ser contextualizada em relação às práticas mais gerais de medicalização da sexualidade. Estudos brasileiros recentes sobre sexologia, em especial o de Jane Russo (2008), argumentam que uma segunda onda de produção sexológica focada nas "disfunçōes sexuais", inaugurada pelos trabalhos de Masters e Jonsons nos anos de 1970, teria substituído nos códigos internacionais de doenças os antigos desvios da norma heterossexual. Nas palavras da autora, na sexologia:

Não se está mais produzindo identidades desviantes ou definindo novos sujeitos na cena pública (como foi o caso, por exemplo, da homossexualidade), mas alargando e pavimentando o caminho para a construção médico-psicológica da performance sexual como ideal de saúde e bem estar (Russo, 2008, p. 7).

Para ela, essa psico-medicalização da heterossexualidade coexiste com a intensa politização da diversidade sexual. Estes processos estariam interligados na medida em que ambos resultam da autonomização da sexualidade em relação à esfera reprodutiva e da ênfase no prazer como objetivo primordial da atividade sexual. Em face desse movimento sexológico mais abrangente, a "deficiência” pode ser pensada como um terreno fértil para a proliferação do conhecimento e das terapêuticas sobre "disfunções sexuais".
Além disso, a problematização da funcionalidade sexual alinha-se ao modelo médico de explicação e manejo da deficiência. Isso pode ser observado pela fragmentação e individualização das pesquisas, geralmente direcionadas para um tipo específico de "deficiência". Nesse sentido, a primeira grande divisão realizada do ponto de vista da construção do objeto é a separação entre desabilidades físicas e mentais/cognitivas e doenças crônicas. Ademais, investigam-se individualmente: lesão na coluna vertebral, surdez (para a qual é direcionado um número especial com cerca de cinco artigos), cegueira, Doença de Huntington, diferentes tipos de câncer, afasia, Síndrome de Turner, stoma, demência, Alzheimer, esclerose múltipla, esquizofrenia, autismo, cistismo, osteoporose, dor crônica, paralisia cerebral, lúpus, Doença de Peyronie, Síndrome de Asperger etc.

Conforme Diniz (2007), esse tipo de abordagem considera a "deficiência" uma condição corporal exclusivamente negativa, que traz prejuízos aos indivíduos. Em razão disso, ela deve ser enfrentada, combatida ou, pelo menos, minimizada em seus reflexos sobre a atividade sexual. Nesse contexto observa-se um dos terrenos mais férteis para o desenvolvimento dos discursos sexológicos que dão sentido à sexualidade por meio de elementos que sejam válidos universalmente, tais como a idéia de pulsão sexual.

\section{A especificidade das mulheres}

A segunda modalidade de problematização da relação entre sexualidade e "deficiência" parte da crítica feminista à centralidade dada ao funcionamento sexual, como uma preocupação eminentemente masculina, direcionada à reabilitação dos homens. Entre os dez volumes analisados, seis números especiais são dedicados à temática das mulheres, além de um sobre gênero e vários outros artigos que ao longo das ediçôes regulares também tratam deste tema. Entre os principais argumentos que sustentam a especificidade da experiência das mulheres desabilitadas está a idéia de dupla opressão: de um lado pela própria condição feminina, de outro, pela condição de pessoa com "deficiência"/desabilitada. Ellen Rubin (1997) ${ }^{12}$, por exemplo, aborda as difi- 
culdades de reabilitação entre mulheres cegas, que precisam ultrapassar uma dupla barreira (interior e exterior) para enfrentar suas desabilidades. Os homens, mesmo sendo cegos, são socializados para enfrentar as dificuldades relativas à sua condição física como desafios exteriores a serem superados. No caso das mulheres, a incapacidade física tende acentuar elementos de domesticidade e dependência que fazem parte da socialização feminina. Além das dificuldades específicas que a reabilitação apresenta no caso da deficiência visual, colocam-se uma série de barreiras subjetivas relativas à ausência de um estímulo para a auto-suficiência bem como da própria crença na superação das dificuldades.

O argumento da dupla opressão torna-se ainda mais eficaz na construção desse tipo de problematização à medida que é operacionalizado no âmbito da sexualidade. Nesse caso, a crítica se dirige às iniciativas de desenvolvimento de tecnologias de reabilitação focadas na disfunção sexual masculina, como se a sexualidade fosse algo de menor importância para as mulheres. No campo da sexologia, os autores apontam a inexistência de alternativas medicamentosas de estímulo à excitação e ao desejo sexual das mulheres. Espera-se que o desenvolvimento de um viagra feminino possa promover uma revolução tão expressiva no acesso ao desempenho sexual das mulheres quanto aquela que vem promovendo entre os homens. ${ }^{13} \mathrm{~A}$ menor associação da mulher à sexualidade seria responsável também pela maior dificuldade das mulheres desabilitadas em acessar informações e educação sexual. Walters, Nosek e Langdon, numa pesquisa que compara as condições de acesso à educação sexual e às informaçôes sobre funcionamento reprodutivo e contracepção, justificam a maior dificuldade das mulheres desabilitadas pela indiferença social e histórica em relação à sexualidade feminina: "Historicamente as mulheres têm sido vistas como empregadas dos homens e potenciais mães e não como seres sexuais. Espera-se delas que ajam como se realmente não tivessem desejo sexual" (2001, p. 168, trad. livre).

Além de promover a investigação da sexualidade feminina no campo da "deficiência", essa perspectiva aponta para um outro foco de discussóes, o do acesso à saúde reprodutiva. Desse modo, atrai para o campo da "deficiência" novas especialidades médicas como a ginecologia e a obstetrícia que vão atuar na pesquisa e no manejo do ciclo menstrual, da menopausa, da infertilidade, das complicaçōes da gravidez, das doenças sexualmente transmissíveis e das estratégias de prevenção e contracepção.

A vulnerabilidade ao abuso e à violência sexual é outra dimensão importante que se torna objeto de problematização a partir da perspectiva da vivência feminina da sexualidade no contexto da "deficiência”. Entre as principais razōes dessa vulnerabilidade são a proximidade e a maior dependência das mulheres desabilitadas em relação aos perpetradores do abuso. Para Beck-Massey é preciso considerar também a existência de uma espécie de aceitação social da violência contra mulheres desabilitadas:

A mulher com deficiência freqüentemente sofre todo o tipo de abusos, muitos dos quais perpetrados sem a consciência e o reconhecimento dessa mulher como ser humano, fato que legitima o próprio abuso. Sendo vista como uma pessoa defeituosa, a mulher deficiente é depreciada, desvalorizada e tratada muitas vezes com desrespeito (Becck-Massey, 1999, p. 271, trad. livre).

Mesmo os artigos que se contrapõem à percepção de uma maior vulnerabilidade, argumentando que os índices de abuso não se distanciam da incidência entre as mulheres em geral, destacam a diferença em relação ao acesso às estratégias de enfrentamento, como condições de expressão e denúncia.

\section{Sexualidades desabilitadas ${ }^{14}$}

A preocupação com os aspectos sociais ligados à deficiência inaugura a participação das ciências sociais, da história e da psicologia social na abordagem da interface entre sexualidade e "deficiência". Entre os primeiros elementos destacados por essa perspectiva está a presunção de assexualidade das pessoas desabilitadas, que já vinha sendo pautada na perspectiva da reabilitação. É vinculado à teoria social da "deficiência" que esse enfoque ganha mais força, pois a unidade de análise se desloca da limitação sexual para as expectativas sociais relativas à sexualidade. Tepper (2000), por exemplo, mostra 
como a própria sexologia durante o século $\mathrm{XX}$, ao eleger o orgasmo como determinador do desempenho e da expressão sexual, além de uma medida da saúde sexual instaura uma espécie de profilaxia da sexualidade. Em sua avaliação, os imperativos culturais do orgasmo e da terapia sexual (no caso da falta dele) reforçam a representação das pessoas desabilitadas como assexuadas ou incapazes sexualmente. Nesse sentido, para o autor criticar a presunção de assexualidade das pessoas desabilitadas demanda mais do que um discurso sobre a necessidade de sexo como critério de qualidade de vida.

Uma das nuanças que podem ser percebidas nos textos identificados com a teoria social da "deficiência” é a mudança de posição das pessoas com "deficiência", que deixam de ser consideradas apenas como "pacientes". Sua atuação não se resume ao consumo de tecnologias e serviços de reabilitação e, ela passa a ocupar o próprio espaço da produção do conhecimento. Nesse sentido, cabe destacar que o modelo social tem sua origem entre ativistas políticos ingleses vinculados à Union of Physically Impaired Against Segregation (Upias). Esse grupo defende que os problemas com a "deficiência” não são causados pelas características corporais em si, mas pela forma opressiva por meio da qual a sociedade lida com a diferença corporal. Desse modo, o modelo social procura imprimir um sentido particular ao termo disability, privilegiando a distinção entre corpos socialmente habilitados e desabilitados.

No que tange à interface com a sexualidade, a aplicação desse modelo implica a tese de que não são os elementos físicos e psicológicos imediatamente decorrentes das condições corporais diferenciadas que desabilitam as pessoas em relação ao exercício da sexualidade, mas sim os padrões de normalidade sexual que não comportam as experiências das pessoas desabilitadas. Dito de outro modo, o que desabilita para o sexo para além da incapacidade corporal e/ou cognitiva são as normas sociais que determinam o que é sexualmente possível e aceitável.

A problematização dos aspectos sociais que desabilitam os indivíduos em relação ao exercício da sexualidade contempla as dificuldades estruturais que ultrapassam as peculiaridades de cada tipo de desabilidade. Segundo Tom Shakespeare (2000), destacam-se a falta de condições de privacidade e de condições financeiras decorrentes de situação de dependência econômica; o estigma vinculado à imagem corporal; a baixa auto-estima e autoconfiança; a dificuldade no estabelecimento de relações interpessoais; a alta incidência de situaçôes traumáticas de abuso sexual (principalmente entre mulheres), dificultando o estabelecimento de laços de confiança para o exercício da sexualidade.

A abordagem relativista da diversidade sexual, que vem encontrando respaldo e amparo conceitual na teoria queer, ${ }^{15}$ é uma das principais características da perspectiva social. Os artigos que discutem a situação de pessoas desabilitadas pertencentes a grupos sexuais minoritários, como faz Odette (1999) em relato de sua experiência pessoal como mulher lésbica e desabilitada, apontam para a insuficiência dos padrôes binários de gênero para descrever a diversidade de expressões que perpassam as relações das pessoas.

A vinculação com a teoria queer permite questionar a um só tempo as modalidades de interações sexuais standard (intercurso penetrativo heterossexual) e os padrões eróticos que elegem como desejáveis apenas determinados tipos corporais. A crítica, principalmente aos padróes estéticos que organizam a produção de desejo legítimo, vai ao encontro de uma posição mais relativizadora de práticas e desejos, como aqueles que pautam o devoteísmo.

Em geral, os artigos constituídos de narrativas de experiência, escritos pelos consumidores do conhecimento científico veiculado pela revista, também podem ser pensados a partir dessa perspectiva social de problematização. Isso acontece, em grande medida, porque tanto no campo da teoria queer, como no interior da escola sociológica de Leeds há uma defesa e um reconhecimento da autoridade da experiência como chave para a produção do conhecimento sobre o tema.

O destaque aos aspectos sociais desabilitadores em relação à sexualidade é simultâneo à mudança de uma prática discursiva alicerçada na promoção da saúde para um outro tipo de discurso, cuja ênfase está no direito, no reconhecimento da cidadania e na busca por uma não patologização da variação e da diversidade corporal e sexual. 


\section{Redes de suporte e assistência}

A quarta perspectiva de abordagem contempla a formação de redes de suporte e assistência ao exercício da sexualidade para pessoas com os mais diversos tipos de "deficiência". Esse tipo de abordagem marca a presença de vários outros grupos profissionais vinculados à área da saúde, como enfermagem, fisioterapia, serviço social, além de uma contribuição mais efetiva da área de educação especial e educação sexual propriamente dita. A questão do suporte e da assistência agrega elementos dos dois modelos teóricos de explicação da "deficiência", o médico e o social. Seu foco é a intervenção direta em face dos mais diferentes tipos de "deficiência" para o exercício da sexualidade. Além da abertura do campo profissional, há que se destacar também a organização das famílias de pessoas desabilitadas em redes de apoio e solidariedade baseadas nas trocas de experiência.

Nesse tipo de texto há um recorte diferenciado em relação ao universo de estudo. Se a perspectiva da funcionalidade sexual delimita sua análise em torno dos indivíduos desabilitados ou das pessoas com "deficiência", a perspectiva feminista preocupa-se especificamente com as mulheres desabilitadas e a perspectiva social procura dar conta dos elementos que compóe a estrutura social mais ampla, os artigos que abordam as redes de suporte e assistência privilegiam os agentes de suporte, os profissionais envolvidos nos processos de reabilitação e inclusão social, os cuidadores, os parceiros e os familiares das pessoas desabilitadas.

O trabalho de Esmail e Munro (2002), por exemplo, sobre o papel dos profissionais da saúde na criação de alternativas para a vida sexual de casais em um dos parceiros possui algum tipo de "deficiência", aponta para a necessidade de uma abordagem terapêutica que contemple também os(as) parceiros(as) das pessoas afetadas por "deficiências" físicas e cognitivas, bem como por doenças crônicas. Uma das principais dificuldades na elaboração de novas formas e sentidos de satisfação sexual é a expectativa de retomar o mesmo tipo de intimidade que constituía a relação sexual antes da deficiência ou da doença. Embora compartilhada pelo casal, muitas vezes é $o$ (a) parceiro(a) não desabilitado que precisa de mais ajuda para superar essa expectativa e engajar-se numa nova dinâmica de interação sexual.

A perspectiva das redes delineia uma forma específica de produção textual, pautada pela cooperação entre profissionais acadêmicos e consumidores, sejam eles as próprias pessoas desabilitadas sejam seus familiares. Exemplo disso, no campo das desabilidades cognitivas, é o material produzido por Robert Strike e David McConnel (2002). Este trabalho mostra a possibilidade de acesso ao casamento, a uma vida sexual ativa e à parentalidade, $o$ que, na maioria das vezes, são aspectos interditados. Além disso, ele também destoa dos demais artigos no que diz respeito à preocupação dos profissionais da saúde (em especial enfermeiros e fisioterapeutas) com os excessos sexuais das pessoas com deficiências cognitivas ou alguns tipos de doenças crônicas associadas à capacidade psíquica.

O texto é uma co-produção entre um pai com desabilidades cognitivas moderadas e um pesquisador (em pós-doutorado) da área do serviço social. Seu propósito é descrever alguns pontos de conflito no exercício parental de pessoas com "deficiências cognitivas", principalmente no que concerne à participação de agentes de suporte na parentalidade. Ao longo do artigo, que pode ser descrito como uma entrevista/diálogo entre os dois autores, Robert Strike usa sua experiência como pai que necessita de suporte para dar sugestôes aos profissionais que trabalham na assistência. Entre os elementos destacados estão: olhar para além do rótulo de deficiente; falar diretamente com a pessoa desabilitada e não por intermédio de outras; apenas ouvir o que o pai/mãe desabilitado tem a dizer não é suficiente, é preciso escutar e respeitar o que ele está dizendo; fazer as coisas com e não para as pessoas desabilitadas. Na conclusão do artigo, ele pondera sobre a colaboração entre as pessoas desabilitadas e os agentes de suporte:

Acho que a primeira coisa que temos a fazer é perguntar o que os pais querem, em vez de deduzir o que eles querem. Certifique-se de que você é capaz de parar o que você está fazendo e mostrar-lhes que você está ouvindo. Você precisa ter certeza de que está entendendo o que a pessoa está dizendo. Em vez de colocar palavras 
na boca das pessoas, é preciso deixar que a pessoa termine de falar para depois fazer a pergunta. Penso que é importante para nós mostrar para as pessoas (que trabalham na assistência) que podemos trabalhar juntos e não um contra o outro (Strike e McConnel, 2002, pp. 62-63, trad. livre).

Esta passagem reafirma o argumento central do texto, qual seja, de que as pessoas com desabilidades cognitivas "têm algo importante a dizer" sobre a sua própria trajetória e sobre o serviço de assistência que lhes é prestado. A questão que se coloca para as pessoas que trabalham no suporte é justamente não fazer as coisas pelas pessoas com deficiência e sim junto com elas. A dependência, portanto, não exclui a possibilidade de fazer escolhas e de tomar decisões, "relativamente autônomas", como fazem todas as outras pessoas.

\section{Sexualidade como fronteira da normalidade}

Essa diversidade de perspectivas remete a uma complexa negociação dos limites entre normalidade e patologia em relação à experiência da diversidade corporal, cognitiva e psíquica, à experiência sexual e aos cruzamentos entre elas. $\mathrm{O}$ estudo de tais negociações não pode estar desvinculado das relações de poder e das disputas de legitimidade social e acadêmica entre os diferentes grupos profissionais que produzem conhecimento nessa área. Procurei descrever em linhas gerais a contribuição de diferentes atores na construção da interface entre essas temáticas, tecendo interpretaçôes sobre as relações estabelecidas entre eles.

Nesta sessão, proponho discutir diferenças na abordagem da sexualidade quanto ao tipo de "deficiência". Para tanto, inicio retomando a discrepância quantitativa em favor da abordagem das "deficiências" físicas. Embora eu não esteja fazendo um estudo do tipo análise de conteúdo, no qual as categorias são mensuradas em relação à freqüência e ao tipo de referência, parece-me imprescindível ressaltar o contraste numérico. Dos mais de trezentos artigos, menos de trinta abordam especificamente essa temática. A maior parte está agrupada em um tópico especial intitulado "Sexualidade entre pessoas com Demência e Alzheimer", publicado no volume 16, número 3, em 1998.

Os demais artigos apresentam-se de modo disperso, aparecendo de maneira mais significativa a partir de 2000. Além disso, muitos deles não se detêm especificamente na questão da sexualidade, mas sim na reprodução e na parentalidade, articulandose assim com uma discussão sobre direitos reprodutivos. Destaco os mais afinados com a perspectiva das redes de suporte e assistência, como o de Strike e McConnel, acima referido, bem como os textos preocupados com os aspectos sociais. Exemplar dessa última perspectiva é o trabalho de Pamela Block (2000 e 2002), que analisa as questóes de parentalidade, fertilidade e os processos de esterilização de mulheres com "deficiências" cognitivas no Brasil e nos Estados Unidos. Ao abordar a questão da sexualidade, a autora defende a normalidade e a positividade da atividade sexual entre pessoas com "deficiência" cognitiva. No entanto, seu trabalho é uma exceção quando comparado aos demais textos que abordam a diversidade cognitiva.

Do ponto de vista etnográfico, tal lacuna pode ser considerada um dado de pesquisa, uma vez que aponta para um tipo de articulação preferencial entre as temáticas sobre sexualidade e "deficiência". Nesse sentido, abundam investigaçôes quantitativas e qualitativas destinadas a explorar a hipótese de um menor desempenho e satisfação sexuais por parte das pessoas fisicamente desabilitadas. Vejamos alguns exemplos.

Taleporos e McCabe revisam a literatura sobre as implicações físicas e as barreiras sociais que comprometem a atividade sexual entre pessoas com desabilidades físicas. Para os autores, o comprometimento físico não implica uma diminuição das necessidades sexuais:

Embora esse estudos demonstrem que a atividade sexual das pessoas com deficiência física sejam limitadas, não há razão para acreditarmos que as necessidades sexuais e amorosas sejam inferiores às da população em geral. De fato, Cummins e Deeks mostraram que as necessidades sexuais das pessoas com deficiências físicas são elevadas. Desse modo, a combinação entre 
pouca experiência sexual e elevada necessidade interfere facilmente na estima sexual das pessoas com deficiência. Entretanto, essa questão vem sendo amplamente ignorada na literatura (Taleporos e McCabe, 2001, p. 113, trad. livre).

Seu objeto de investigação é a relação entre estima sexual e auto-estima dos sujeitos. Descrevendo experiências individuais em que não há diminuição da satisfação sexual, pelo contrário, em que se observa uma aquisição de maior criatividade e versatilidade sexuais, os autores concluem que a "deficiência" não pode ser tomada como determinante de uma baixa estima sexual. Tais exemplos devem ser explorados, segundo eles, no aconselhamento de pessoas que enfrentam dificuldades dessa ordem (Idem).

Outro artigo interessante é o de Irzyniek e LewStarowicz sobre a vida sexual de mulheres com síndrome de Turner. A citação a seguir mostra a discussão decorrente da dos dados sobre a diferença entre a vida sexual das mulheres com síndrome de Turner em relação às mulheres que não possuem a doença:

A vida sexual é uma das atividades mais essenciais para a mulher e determina sua qualidade de vida. O reconhecimento dessa esfera é de grande importância para os médicos que atendem pacientes com Síndrome de Turner. Como dissemos anteriormente, uma porcentagem alta das mulheres com Turner demonstra pouco interesse por homens, retardam sua iniciação sexual ou mesmo não se relacionam sexualmente, se comparadas às mulheres que não apresentam essa doença (Irzyniek e LewStarowicz, 2006, p. 210, trad. livre).

Conforme nos mostra Machado (2005) sobre as patologias associadas à diferenciação sexual, há uma preocupação especial por parte dos médicos na normalização sexual dessas pacientes, em vista da legitimação do sexo feminino assignado. ${ }^{16}$ Recomenda-se uma maior atenção nessa dimensão sexual da vida dessas pacientes, inclusive para que os médicos possam ajudá-las em suas dificuldades. Mais do que anular o efeito negativo da "deficiência" física, a retomada da vida sexual é pensada como um importante aliado no controle ou no enfrentamento da própria deficiência ou patologia. Em tais casos, é percebida como normal (como uma evidência de melhora) a iniciativa do indivíduo em procurar apoio para a retomada de sua vida sexual, inclusive no caso da manutenção de vínculos conjugais preexistentes.

Os psicólogos Andrew Walters e Gail Williamson defendem a existência de uma forte correlação entre o exercício da sexualidade e a qualidade de vida das pessoas com "deficiências" físicas. Num estudo com pessoas amputadas (1998), eles destacam que o incremento da auto-estima, a melhora da auto-imagem e da imagem corporal estariam diretamente implicados na visão de si como alguém atraente e desejável sexualmente. Nesse sentido, os autores encorajam os profissionais a estimularem a expressão da sexualidade.

Todos esses exemplos levam a pensar que quando se trata de "deficiências" físicas, bem como doenças fisiológicas crônicas, o interesse pela sexualidade, as iniciativas de reabilitação e o exercício da sexualidade em si operam como uma espécie de fronteira de acesso à normalidade. A prática sexual é vista como algo que não traz prejuízos ou agravos para a condição física do indivíduo, pelo contrário numa perspectiva mais ampla de saúde, ela é considerada saudável e benéfica. Até mesmo do ponto de vista da inclusão social, a inserção dos indivíduos nos programas de educação sexual, a abordagem para prevenção de doenças, a capacidade de despertar interesse erótico operam de modo a diminuir o estigma e a distinção pejorativa das pessoas desabilitadas.

No entanto, quando o assunto são as desabilidades cognitivas ou doenças crônicas que perturbam a sanidade mental (como a demência e o mal de Alzheimer, por exemplo) a presença de atividade sexual aparece nos artigos como um elemento que reforça a própria deficiência, ou que coloca entraves para o seu manejo. Essa tendência é expressa nos próprios títulos dos artigos, que passam a enfatizar expressōes inadequadas, excessivas, impróprias e perversas da sexualidade. Nesses casos, não é a falta de sexo que é percebida como problemática, já que do ponto de vista corporal essas pessoas se encontram plenamente habilitadas para atividade sexual, 
mas a busca de uma parceria sexual ou a manifestação pública da sexualidade é que é em si considerada problemática. Prevalece nos artigos a idéia de sexualidade descontrolada, exacerbada e doentia.

O texto de Katlen Mayers realiza um survey entre profissionais de saúde que trabalham com idosos institucionalizados sobre o comportamento sexual dos internos. A ênfase do artigo são os abusos sexuais cometidos por internos, homens e mulheres, contra os próprios profissionais de saúde e contra outros pacientes. Os dados mostram a freqüência das ocorrências nesse sentido indicadas pelos profissionais de saúde a partir de sua experiência e observação das atitudes sexuais dos internos. Práticas como "toques nos seios", "toques nas nádegas", propostas de conteúdo sexual, masturbação, de carícias sexuais entre os pacientes, entre outras são percebidas pelas cuidadoras como formas de abuso. A análise que empreendem a partir desses dados tem como principal objetivo prevenir a vitimização de profissionais e pacientes em relação aos excessos sexuais:

Alguns cuidadores acreditam que o comportamento dos pacientes pode predizer atitudes sexualmente agressivas. Eles afirmam que os agressores sexuais verbalizam coisas sobre sexualidade, se engajam em atividades de autoestimulação, masturbação e inspeção das partes privadas do corpo dos outros. Segundo um cuidador, os homens queriam mostrar seus genitais para as mulheres e tentaram puxálas para dentro dos quartos. Observar esses comportamentos tem sido útil para prevenir a ocorrência de agressão sexual. Membros da equipe indicaram que a maior parte dos comportamentos preditivos da vitimização sexual é a verbalização sexual e a masturbação (Mayers, 1998, p. 222, trad. livre).

Nesses casos, as atitudes sexuais são justificadas pela própria doença, sendo consideradas uma manifestação da própria demência.

Mesmo entre os artigos que não consideram patológicas as expressões sexuais socialmente inapropriadas, como o texto do "educador especial" Anthony Walsh (2000), há um investimento no desenvolvimento de estratégias de controle ou domesticação de práticas como a masturbação, inapropriadas entre pacientes com "deficiências" cognitivas severas. Não se trata de combater a masturbação (que em si é considerada positiva), mas de criar estratégias para que ela aconteça de forma mais apropriada. $\mathrm{O}$ autor propõe intensificar a preocupação e a responsabilidade dos cuidadores com a melhora dos pacientes, modificando o tipo de resposta dada à masturbação inadequada. ${ }^{17}$ Outra "educadora especial”, Rebecca Koller (2000), ao abordar a sexualidade entre adolescentes com autismo também defende a necessidade de educação sexual no que diz respeito à promoção de um autoerotismo mais adequado às normas sociais, à autoproteção em relação ao abuso e ao suporte ante o direcionamento do desejo sexual a outras pessoas.

A sexualidade masturbatória (e poderíamos acrescentar também as demais práticas não penetrativas), como bem descreve Foucault (2001) no curso sobre "Os anormais" ministrado na década de 1970 no College de France, foi considerada propulsora de todas as anomalias no século XIX. Pode-se observar, nos artigos aqui analisados, que tal sexualidade continua servindo como manifestação e, ao mesmo tempo, como prova de anormalidade. Creio, dessa forma, que as manifestações da sexualidade entre pessoas com "deficiências" cognitivas são abordadas muito mais em relação ao desconforto e à perturbação que causam às outras pessoas, em especial os familiares e cuidadores. O efeito de fronteira operado pela sexualidade alarga ainda mais o espectro de anormalidade que assombra a variabilidade cognitiva. Muito raras são as iniciativas que procuram compreender de maneira positiva tais expressões sexuais, ou que investem na reabilitação e na promoção da sexualidade.

\section{Considerações finais}

Uma das principais virtudes da etnografia, segundo Peirano (1995), é que geralmente os dados apresentados ultrapassam as interpretações do antropólogo. Partindo desse preceito, este artigo teve como principal finalidade servir de convite e estímulo para que estudiosos da sexualidade e das relações de gênero observem mais de perto a 
temática das "deficiências" e, principalmente, analisem com mais acuidade o conteúdo dos artigos, para além daquilo que a leitura apresentada permite compreender.

Seguramente, grupos religiosos, entidades filantrópicas, Ongs, ativistas políticos e associações de pessoas com "deficiência" aguardam respostas cientificamente embasadas sobre as possibilidades sexuais, bem como sobre estratégias menos repressivas de manejo da sexualidade e das intençōes reprodutivas de pessoas com diferentes tipos de deficiências físicas, cognitivas ou com doenças crônicas.

A partir da análise dos artigos publicados ao longo de dez anos na revista Sexuality and Disabili$t y$, procurou-se descrever a emergência da interface sexualidade e "deficiência" com base em quatro diferentes formas de problematização. é dialogando com essas diferentes perspectivas - funcionalidade sexual, especificidade das mulheres, desabilitação e redes de suporte e assistência —, é que os cientistas sociais poderão produzir novas interpretações sobre essa interface. Mais do que isso, a leitura das "deficiências" em termos de variabilidade corporal traz novas interpelações sobre as convenções corporais em torno da sexualidade.

Ao suscitar discussões em torno da relativização do corpo e das potencialidades físicas e cognitivas, essa análise apresenta questôes desafiadoras às clássicas teorias do construtivismo social. Acostumadas a privilegiar a dimensão história, contextual e simbólica da sexualidade, as teorias parecem pouco confortáveis diante da necessidade de retorno ao corpo como lócus da diferença (Vance e Adress, 1989). Para fazer frente a essas questões, a discussão construtivista precisa reencontrar o caminho do diálogo com a sexologia e com a medicina, para além das já desgastadas críticas à abordagem essencialista.

\section{Notas}

1 A grafia entre aspas da palavra deficiência ao longo do artigo objetiva assinalar a dificuldade de tradução do termo inglês disability para o português e a imprecisão do termo deficiência. Ao mesmo tempo visa estabelecer uma distinção entre utilização e menção do termo.
As aspas indicam a menção ao conceito médico de deficiência, o qual não subscrevo ao longo do artigo. Sua referência no texto como designativa do objeto em questão justifica-se por uma questão de comunicação, tendo em vista que historicamente o conceito adquiriu um caráter de verdade oficial, sendo incorporado ao senso comum.

2 A revista é publicada pela editora Springer, que trabalha com periódicos internacionais nas áreas de ciência, tecnologia, matemática e medicina. Tendo iniciado em 1978, ela seguiu sendo publicada periodicamente até 1984. O oitavo volume foi publicado em 1987 quando houve uma nova interrupção de três anos. $\mathrm{O}$ nono volume e a sequiência anual regular foram retomados em 1991. Dos primeiros quinze volumes estão disponíveis até o momento apenas os títulos dos artigos e os autores.

3 A organização dessas instituições, principalmente nos Estados Unidos e na Inglaterra, ocorreu num contexto marcado pela industrialização e urbanização das cidades (cuja conseqüência inevitável é a proliferação de acidentes de trânsito e de trabalho) e pela atuação desses países em diferentes guerras ao longo do século XX.

4 Para a revista, são considerados consumidores as próprias pessoas com "deficiência", à medida que para elas é que se dirigem o conhecimento, as técnicas e as estratégias terapêuticas apresentadas pela revista.

5 Trata-se do Projeto "Difundindo os Direitos Sexuais e Reprodutivos da América Latina” realizado entre 2005 e 2007, junto ao Observatório de Direitos Humanos da Universidade Federal do Rio Grande do Sul, sob a coordenação dos professores Daniela Riva Knauth e Fernando Sefner.

6 Refiro-me em especial a Almeida (2005).

7 Nesses números a nota do editor é sucedida por uma introdução e o prefácio é redigido pelo editor convidado. Podem ser compostos por artigos produzidos por um mesmo grupo de pesquisa, ou o próprio editor convidado faz contatos com autores estrangeiros que trabalham com a temática proposta, além de procurar abordagens distintas para diversificar as perspectivas.

8 Por exemplo, no primeiro número do volume $15 \mathrm{pu}-$ blicado em março de 1997, a maior parte foi dedicada ao detalhamento da programação, com resumos e principais artigos do "Seminário Internacional de Mulheres e Deficiência". Havia desde textos políticos de militantes feministas, até apresentação dos resultados de pesquisas sobre os principais problemas enfrentados pelas mulheres nos processo de reabilitação e também relatos de prática clínica ginecológica. 
9 Observação similar é evidenciada na tese de Malcher (2007) sobre as tentativas de criação da Andrologia como especialidade médica, distinta da Urologia. Tal investimento caracterizava-se pela busca de diferentes referenciais em fisiologia, psicologia, estudos de patologia sexual, relatos de casos hospitalares e de terapêuticas, entre outros, a fim de justificar a especificidade e a importância da andrologia dentro da medicina.

10 Devoteísmo é o termo utilizado para descrever atração ou desejo erótico vinculado à condição corporal diferenciada ou deficiência. Do ponto de vista psiquiátrico, essa atração é caracterizada como parafilia, ou seja, um transtorno do desejo sexual.

11 Vale lembrar que não apenas os comportamentos que se distanciam da norma heterossexual são tomados em si como patológicos, mas também são associados a outros tipos de patologias, como a Aids, o uso de drogas e o alcoolismo. Na próxima sessão analiso em detalhe os deslocamentos entre os limites de normalidade em relação à deficiência a partir da sexualidade.

12 A autora é coordenadora de programas em prol da igualdade de educação para pessoas desabilitadas.

13 Apesar dessa expectativa por parte dos sexólogos, Ducharme (2005) assinala a existência de uma série de controvérsias relacionadas à desconfiança quanto à participação das indústrias farmacêuticas nas pesquisas e também à desconfiança da efetividade do próprio medicamento na resolução do problema, sem considerar a influência de outros aspectos, tais como a moralidade sexual, o stress, a emoção, o tipo de relacionamento, as condições de conforto, a idade, as características religiosas e culturais etc.

14 A tradução corrente da palavra disability para o português é incapacidade ou deficiência. No entanto, a fim de contemplar o sentido proposto no contexto da teoria social, optei pelos termos desabilitação ou desabilidade, nos casos em que os autores endossam esse modelo teórico. Esses termos possibilitam uma leitura que acentua a arbitrariedade social da divisão entre corpos habilitados e desabilitados e, portanto, descrevem de forma mais adequada o sentido conferido pela teoria social à palavra disability.

15 O termo queer, que significa "torcido", "oblíquo", "esquisito", era usado nos Estados Unidos e na Inglaterra em tom de rejeição e degradação para se referir aos gays, lésbicas e transgêneros. Entretanto, no final dos anos de 1980 foi reapropriado de modo afirmativo para se referir a todos os indivíduos cuja sexualidade extrapolasse os limites da heterossexualidade binária.
16 No contexto das Desordens do Desenvolvimento Sexual (DSD), o processo de assignação sexual diz respeito às decisões tomadas para a designação do sexo e para a correção dos genitais.

17 Inadequada, segundo Walsh (2000), é a masturbação praticada no lugar e hora errados, que cause qualquer tipo de lesão à genitália, em que a freqüência possa perturbar o exercício de outras atividades, que causa desconforto à própria pessoa ou às outras.

\section{BIBLIOGRAFIA}

ADDRESS, Keynote \& VANCE, Carole. (1989), "Social Construction theory: problems in the history of sexuality", in D. Altman et al. Which homossexuality? Essays from the International Conference on Lesbian and Gay studies, Londres, GMP Publischer, pp. 13-34.

ALMEIDA, Francis Moraes. (2005), Heranças perigosas: arquegenealogia da legislação penal brasileira. Porto Alegre, dissertação de mestrado em Sociologia, Universidade Federal do Rio Grande do Sul.

BECK-MASSEY, Débora. (1999), "Sanctioned war: women, violence, and disabilities". Sexuality and Disability, 17 (3): 269-276.

BOLCK, Pamela. (2000), "Sexuality, fertility, and danger: Twentieth-Century images of women with cognitive disabilities". Sexuality and Disability, 18 (4): 239-254.

. (2002), "Sexuality, parenthood, and cognitive disability in Brazil". Sexuality and Disability, 20 (1): 7-28.

CAMARGO Jr., Kenneth. (2003), Biomedicina, saber e ciência. São Paulo, Hucitec.

DINIZ, Débora. (2007), O que é Deficiência? São Paulo, Brasiliense.

DUCHARME, Stanley. (2005), "From Editor". Sexuality and Disability, 23 (3): 117-120.

ELMORE, James. (2000), "Fluoxetine-Associated remission of ego-dystonic male homosexuality". Sexuality and Disability, 20 (2): 149-151.

ESMAIL, Shaniff; ESMAIL, Yashima \& MUNRO, Brenda. (2001), "Sexuality and disability: the role of the health care professionals in provid- 
ing options and alternatives for couples". Sexuality and Disability, 19 (4): 267-282.

FOUCAULT, Michel. (2001), Os Anormais. São Paulo, Martins Fontes. . (2004), Ética, sexualidade e política: ditos e escritos $V$. Rio de Janeiro, Forense Universitária.

GIAMI, Alain. (2004), O anjo e a fera: sexualidade, deficiência mental, instituição. São Paulo, Casa do Psicólogo.

HELMAN, Cecil. (2003), Cultura, saúde e doença. Porto Alegre, ArtMed.

IRZYNIEC, Tomasz \& LEW-STAROWICZ, Zbigniew. (2006), "Sexual life and lifestyle of women with Turner's Syndrome". Sexuality and Disability, 24 (4): 207-212.

KOLLER, Rebecca. (2000), "Sexuality and adolescents with autism". Sexuality and Disability, 18 (2): 125-135.

LATOUR, Bruno. (2004), A ciência em ação. São Paulo, Editora da Unesp.

MACHADO, Paula Sandrine. (2005), "O sexo dos Anjos: um olhar sobre a anatomia e a produção do sexo (como se fosse) natural". Cadernos Pagu, 24: 249-281.

MALCHER, Leonardo. (2007), Aos cuidados de Príapo: impotência sexual masculina, medicalização e tecnologia na medicina do Brasil. Porto Alegre, tese de doutorado em Antropologia Social, Universidade Federal do Rio Grande do Sul.

MAYERS, Kathleen. (1998), "Sexuality and the demented patient". Sexuality and Disability, 16 (3): 219-225.

MENEZES, Rachel. (2004), Em busca da boa morte: antropologia dos cuidados paliativos. Rio de Janeiro, Garamond/Fiocruz.

MILLIGAN, Maureen \& NEUFELD, Aldred. (2001), "The myth of asexuality: a survey of social and empirical evidence". Sexuality and Disability, 19 (2): 91-109.

ODETTE, Catherine. (1999), "Butchdon and disability: consumer perspective". Sexuality and Disability, 17 (1): 93-96.

PEIRANO. Mariza. (1995), A favor da etnografia. Rio de Janeiro, Relume Dumará.

RUSSO, Jane. (2008), "Sexualidade e saúde: a produção médico-psicológica de uma vida sexual plena". Trabalho apresentado na Reunião Brasileira de Antropologia, Porto Seguro.

RUBIN, Ellen. (1997), "Rehabilitation problems of women who are blind". Sexuality and Disabily, 15 (1): 41-45.

SHAKESPEARE, Tom. (1999), "The sexual politics of disabled masculinity". Sexuality and Disability, 17 (1): 53-64. . (2000), "Disabled sexuality: toward rights and recognition". Sexuality and Disability, 18 (3): 159-166.

STRIKE, Robert \& McCONNEL, David. (2002), "Look at me, listen to me, I have something important to say". Sexuality and Disability, 20 (1): 53-63.

TALEPOROS, George \& McCABE, Marita. (2001), "Physical disability and sexual esteem". Sexuality and Disability, 19 (2): 131-148.

TEPPER, Mitchel. (1997), "Editorial: Guidelines to address the fluid issue of readiness". Sexuality and Disability, 15 (3): 129-130.

(1997), "Use of sexually explicit films in spinal cord injury rehabilitation programs". Sexuality and Disability, 15 (3): 167-181. (2000), "Sexuality and disability: the missing discourse of pleasure". Sexuality and Disability, 18 (4): 283-290.

VIANNA, Adriana. (2006), "Etnografando documentos". Trabalho apresentado no Seminário Internacional Poéticos do Inventário: Coleções, Listas, Séries e Arquivos na Cultura Contemporânea, Belo Horizonte, Universidade Federal de Minas Gerais/Universidade de Standford, maio-jun.

WALSH, Anthony. (2000), "Improve and care: responding to inappropriate masturbation in people with severe intellectual disabilities". Sexuality and Disability, 18 (1): 27-39.

WALTERS, Andrew \& WILLIAMSON, Gail. (1998). "Sexual satisfaction predicts quality of life: a study of adult amputees". Sexuality and Disability, 16 (2): 103-115.

WALTER, Laurie; NOSEK, Margareth \& LANGDON, Karen. (2001), "Understanding of sexuality and reproductive health among women with and without physical disabilities". Sexuality and Disability, 19 (3): 167-176. 
CORPO E OUTRAS (DE)

LIMITAÇŌES SEXUAIS: UMA

ANÁLISE ANTROPOLÓGICA

DA REVISTA SEXUALITY AND

DISABILITY ENTRE OS ANOS DE

1996 E 2006

\section{Nádia Elisa Meinerz}

Palavras-Chave: Sexualidade; Corpo; Diversidade; Deficiências; Reabilitação.

O objetivo deste artigo é descrever a emergência da interface entre sexualidade e "deficiências" como problema de pesquisa e intervenção. Para tanto, são analisados artigos de uma revista internacional intitulada Sexuality and Disability, publicados entre os anos de 1997 e 2006. Foram identificadas quatro perspectivas de articulação entre as temáticas que remetem a diferentes questôes de pesquisa, modelos específicos de explicação da "deficiência”, além de posiçôes variáveis em relação à produção, aplicação e consumo do conhecimento científico. A análise aponta também para a sexualidade como dispositivo de fronteira, definidor dos limites entre normalidade e patologia em relação à experiência da diversidade corporal e psíquica/cognitiva.
THE BODY AND OTHER SEXUAL (DE)LIMITATIONS: AN ANTHROPOLOGICAL ANALYSIS OF THE MAGAZINE SEXUALITY AND DISABILITY BETWEEN 1996 AND 2006

\section{Nádia Elisa Meinerz}

Keywords: Sexuality; Body; Diversity; Deficiencies; Rehabilitation.

This article aims at describing the emergence of the interface between sexuality and "deficiencies" as both research and intervention problem. We analyze articles from the international magazine Sexuality and Disability, published between 1997 and 2006. Four articulation perspectives have been identified amidst themes addressing different research matters, specific models explaining such "deficiency," as well as variable positions regarding production, application, and consumption of scientific knowledge. The analysis also points at sexuality as a boundary device, defining the limits between normality and pathology relating to the experience of corporal and psychic/cognitive diversity .
LE CORPS ET D'AUTRES (DÉ) LIMITATIONS SEXUELLES: UNE ANALYSE ANTHROPOLOGIQUE DE LA REVUE SEXUALITY AND DISABILITY ENTRE LES ANNÉES 1996 ET 2006

\section{Nádia Elisa Meinerz}

Mots-clés: Sexualité; Corps; Diversité; Insuffisances; Réhabilitation.

L'objectif de cet article est de décrire l'émergence de l'interface entre la sexualité et les "insuffisances" en tant que problème de recherche et d'intervention. Pour cela, l'auteur analyse des articles d'une revue internationale intitulée Sexuality and Disability, publiés entre les années 1997 et 2006. Il a identifié quatre perspectives d'articulation parmi les thèmes qui renvoient à différentes questions de recherche, de modèles spécifiques d'explication de l'insuffisance", outre les positions variables par rapport à la production, l'application et la consommation de la connaissance scientifique. L'analyse conduit également vers la sexualité en tant que dispositif de frontière, définisseur des limites entre la normalité et la pathologie face à l'expérience de la diversité corporelle et psychique/cognitive. 